\title{
Study on the measurement of isoprene by differential optical absorption spectroscopy
}

\author{
Song Gao ${ }^{1,2}$, Shanshan Wang ${ }^{1,3}$, Chuanqi Gu ${ }^{1}$, Jian Zhu ${ }^{1}$, Ruifeng Zhang ${ }^{1}$, Yanlin Guo ${ }^{1}$, Yuhao Yan ${ }^{1}$, and \\ Bin Zhou ${ }^{1,3,4,5}$ \\ ${ }^{1}$ Shanghai Key Laboratory of Atmospheric Particle Pollution and Prevention (LAP ${ }^{3}$ ), Department of Environmental Science \\ and Engineering, Fudan University, Shanghai, 200438, China \\ ${ }^{2}$ Shanghai Environmental Monitoring Center, Shanghai, 200235, China \\ ${ }^{3}$ Institute of Eco-Chongming (IEC), No. 20 Cuiniao Road, Shanghai, 202162, China \\ ${ }^{4}$ Zhuhai Fudan Innovation Institute, Zhuhai, 519000, China \\ ${ }^{5}$ Institute of Atmospheric Sciences, Fudan University, Shanghai, 200433, China
}

Correspondence: Shanshan Wang (shanshanwang@fudan.edu.cn) and Bin Zhou (binzhou@ fudan.edu.cn)

Received: 31 July 2020 - Discussion started: 27 October 2020

Revised: 19 January 2021 - Accepted: 3 March 2021 - Published: 7 April 2021

\begin{abstract}
In this paper, the continuous online measurements of isoprene in the atmosphere have been carried out by using differential optical absorption spectroscopy (DOAS) in the band of 202.71-227.72 nm for the first time. Under a zero optical path in the laboratory, different equivalent concentrations of isoprene were measured by the combination of known concentrations of gas and series calibration cells. The correlation between the measured concentrations and the equivalent concentrations was 0.9995 , and the slope was 1.065. The correlation coefficient between DOAS and the online volatile organic compound (VOC) instrument observed from $23 \mathrm{~d}$ of field observations is 0.85 with a slope of 0.86 . It was estimated that the detection limit of isoprene with DOAS is approximately $0.1 \mathrm{ppb}$ at an optical path of $75 \mathrm{~m}$, and it was verified that isoprene could be measured in the ultraviolet absorption band using the DOAS method with high temporal resolution and a low maintenance cost.
\end{abstract}

\section{Introduction}

Isoprene, named as 2-methyl-1,3-butadiene $\left(\mathrm{C}_{5} \mathrm{H}_{8}\right)$, is an important BVOC (biogenic volatile organic compound) in the atmosphere. Its global emission rate is about $500 \mathrm{Tg} \mathrm{C} \mathrm{yr}^{-1}$ (Sindelarova et al., 2014). Isoprene accounts for $70 \%$ of global BVOC emissions (Aydin et al., 2014). Land vegetation and other natural sources contribute $90 \%$ of isoprene in the atmosphere (Zhang et al., 2016), and anthropogenic emissions mainly come from industrial activities. Isoprene, as a typical pentadiene hydrocarbon, has a higher activity than ordinary anthropogenic VOCs (Lian et al., 2020), and its lifetime in the boundary layer is only about half an hour (Zheng et al., 2015). Due to high volatility and reaction activity, isoprene can accelerate the reaction between atmospheric substances, and it easily reacts with strong oxidizing substances $\left(\mathrm{OH}, \mathrm{NO}_{3}\right.$ radicals, etc.) and also affects the balance between $\mathrm{NO}_{x}\left(\mathrm{NO}_{x}=\mathrm{NO}+\mathrm{NO}_{2}\right)$ and $\mathrm{O}_{3}$ in the atmosphere. Isoprene is also the precursor of secondary organic aerosol (SOA) (Zeng et al., 2018).

Isoprene produced by plants is a byproduct of photosynthesis; its emission intensity directly relates to the abundance of plants, leaf area index and plant species. Meteorological parameters, such as temperature, radiation intensity and humidity, can also affect isoprene emissions (Bai, 2015). In the daytime, the chemical process oxidized by $\mathrm{OH}$ is the main sink of isoprene. Due to the existence of multiple double bonds, the additional reaction with $\mathrm{OH}$ will lead to the formation of a variety of products and the formation of $\mathrm{RO}_{2}$. In the presence of $\mathrm{NO}_{x}, \mathrm{RO}_{2}$ can be further reacted to convert $\mathrm{RO}$ and $\mathrm{HO}_{2}$, causing the mutual conversion of free radicals and the accumulation of ozone, which affects the balance of $\mathrm{O}_{3}$ in the atmosphere (Chen et al., 2020; Lu et al., 2018; Zhu et al., 2020). Meanwhile, the reaction of isoprene with $\mathrm{NO}_{3}$ mainly occurs at night. Although the reaction only accounts 
for $6 \%-7 \%$ of the total isoprene oxidation, it is an important way to remove $\mathrm{NO}_{3}$ (Xie et al., 2013).

In recent years, with the increase in urban vegetation diversity, the emission intensity of urban BVOCs has shown a significant upward trend. The monitoring and control of isoprene in urban ecosystems have also attracted increasing attention. Because the isoprene concentration in the atmosphere is low and its lifetime is short, highly precise and accurate methods are needed for monitoring. Currently, general methods, including gas chromatography-mass spectrometry (GC-MS), proton transfer reaction mass spectrometry (PTRMS), and chemical ionization mass spectrometry (CIMS), have been introduced to measure isoprene.

GC-MS utilizes the high separation ability of gas chromatography to separate the components of environmental samples and then measures the different compounds with the mass spectrometer. With the advantages of high precision and stability, GC-MS can distinguish most VOCs qualitatively and quantitatively; however, it is difficult to maintain and operate due to the complex requirements of power, temperature control and special carrier gas. GC-MS measurement generally requires sampling, preservation and pretreatment before analysis. During this process, the sample may change to some extent, resulting in inaccurate results.

PTR-MS involves the chemical ionization of a gas sample through proton transfer in a drift tube. The proton source is usually $\mathrm{H}_{3} \mathrm{O}^{+}$. The fixed length of the drift tube provides a fixed reaction time for the ions as they move along the drift tube. The sample air is continuously pumped through the drift tube, and the VOCs in the sample react with $\mathrm{H}_{3} \mathrm{O}^{+}$ to be ionized and then enter the mass spectrometer to be detected. The disadvantage of PTR-MS is that it completely relies on mass spectrometry to provide the identification of mixtures. VOCs are a class of substances; it is possible to have the same molecular weight or the same mass of fragment ions and parent ions. In this case, it is difficult to determine all species present and their respective concentrations. A solution to this is to combine GC with PTR-MS (Blake et al., 2009).

CIMS (Leibrock and Huey, 2000) retains the qualitative ability of mass spectrometry and couples the traditional air sampler with mass spectrometry technology. However, this method is not sensitive to low concentrations of isoprene. In addition, the VOC composition in the atmosphere is complex, and an unknown composition may react with the benzene reagent to interfere with the measurement results. Table 1 lists the comparison of the performance of these three methods for isoprene measurements together with the differential optical absorption spectroscopy (DOAS) method in this study.

In addition, a portable gas chromatograph (iDirac) equipped with a photo-ionization detector to measure isoprene was proposed by Bolas et al. (2020) at Cambridge University. The instrument is an improved technology for GCMS that can work independently for weeks to months in the field environment. Previous studies have rarely mentioned the measurement of isoprene by spectral methods. Brauer et al. (2014) measured the infrared spectrum of isoprene by Fourier transform spectrometer and found that isoprene has a strong absorption near $11000 \mathrm{~nm}$, which provides a new possibility for the measurement of isoprene by spectral technology. So far, however, few people have mentioned the measurement of isoprene by ultraviolet spectroscopy. In this paper, an online measurement method with high temporal resolution for isoprene in the atmosphere is proposed by using DOAS technology in the far ultraviolet band.

\section{Measurement method}

\subsection{Instrument introduction and spectral analysis}

DOAS technology was initially proposed by Platt et al. $(1979,1980)$ in the 1970 s. The principle of the instrument has been detailed in other literature (Platt and Stutz, 2008), so the following is a description of deep UV-DOAS. The system is mainly composed of a light source, transmitting telescope, receiving telescope, spectroscope, and computer, etc. (see Fig. 2). The transmitting and receiving telescopes are located at both ends of the measuring optical path with a distance of $75 \mathrm{~m}$. Since the measurement of isoprene detects the absorption in deep ultraviolet light, we choose a deuterium lamp (L6311-50, Hamamatsu, 35 W) as the light source. The aperture of the transmitting telescope is $76 \mathrm{~mm}$, with a UV-enhanced spherical mirror with a focal length of $304 \mathrm{~mm}$. The aperture of the receiving telescope is $152 \mathrm{~mm}$ with a UV-enhanced spherical mirror with a focal length of $608 \mathrm{~mm}$. A spectroscope (B\&W TEK Inc. BRC741E-1024) with a spectral range of $185-400 \mathrm{~nm}$, a spectral resolution of $0.75 \mathrm{~nm}$ FWHM (full width at half maximum), and a 1024pixel photodiode array was used as the detector to record the spectrum. In the measurement routine, the light emitted by the light source is collimated by the transmitting telescope and then sent out. After a certain distance of transmission, it is collected by the receiving telescope and focused on the incident end of the optical fiber. The optical fiber feeds the light into the spectroscope, which detects the light signal and sends it to the computer for spectral analysis.

The measured atmospheric spectrum contains the absorption information of molecules in the atmosphere. After removing the Rayleigh scattering and Mie scattering, as well as the broadband absorption of molecules by high-pass filtering, the so-called differential absorption spectrum is obtained. This high-pass filtering is performed by a high-pass binomial on the spectrum using the 500 iterations twice to eliminate the broadband structures. The concentration of the corresponding atmospheric components can be retrieved by fitting the differential absorption spectrum with the differential absorption cross section of the measured molecules. The reference spectrum during laboratory experiments was 
Table 1. Comparison of different online methods for isoprene measurement.

\begin{tabular}{|c|c|c|c|c|}
\hline & $\begin{array}{l}\text { DOAS } \\
\text { (this study) }\end{array}$ & $\begin{array}{l}\text { GC-MS } \\
\text { (Gong et al., 2018) }\end{array}$ & $\begin{array}{l}\text { PTR-MS } \\
\text { (Eerdekens et al., 2009) }\end{array}$ & $\begin{array}{l}\text { CIMS } \\
\text { (Leibrock et al., 2003) }\end{array}$ \\
\hline Time resolution & $1 \mathrm{~min}$ & $30-60 \mathrm{~min}$ & $0.5-2 \mathrm{~min}$ & $1.65 \mathrm{~s}$ \\
\hline $\begin{array}{l}\text { Accuracy } \\
\text { (correlation with } \\
\text { GC-MS/GC) }\end{array}$ & $R=0.85$ & $\begin{array}{l}R>0.99 \\
\text { (with offline) }\end{array}$ & $R=0.95$ & $R=0.78$ \\
\hline Detection limit & $10 \mathrm{ppt}$ & $4 \mathrm{ppt}$ & $100 \mathrm{ppt}$ & $<30 \mathrm{ppt}$ \\
\hline Platform & $\begin{array}{l}\text { Stationary/conditional } \\
\text { mobile }\end{array}$ & Stationary/mobile & Stationary/mobile & Stationary/mobile \\
\hline Advantages & $\begin{array}{l}\text { No sampling } \\
\text { Easy operation } \\
\text { Simple instrument }\end{array}$ & $\begin{array}{l}\text { High precision } \\
\text { Accurate quantification }\end{array}$ & $\begin{array}{l}\text { Fast responses } \\
\text { High precision }\end{array}$ & $\begin{array}{l}\text { High time resolution } \\
\text { Good sensitivity }\end{array}$ \\
\hline Disadvantages & $\begin{array}{l}\text { Impacted by weather } \\
\text { conditions } \\
\text { Impacted of interferences }\end{array}$ & $\begin{array}{l}\text { Time-consuming } \\
\text { Calibration needed } \\
\text { Difficult operation and } \\
\text { maintenance }\end{array}$ & $\begin{array}{l}\text { Molecule or fragment ion } \\
\text { of the same mass cannot } \\
\text { be differentiated }\end{array}$ & $\begin{array}{l}\text { Interference of unidenti- } \\
\text { fied components } \\
\text { Expensive equipment }\end{array}$ \\
\hline
\end{tabular}

recorded by receiving a light beam close to the transmitting device, suggesting a zero light path and no absorption of isoprene. In the field measurements, the measured atmospheric spectrum collected at 00:00 LT on 1 July 2018 was used as the reference spectrum considering it is "clean" without isoprene absorption.

Isoprene has strong absorptions between $200.0-225.0 \mathrm{~nm}$, among which there are relatively obvious absorption peaks (Martins et al., 2009) near 210.0, 216.0 and $222.1 \mathrm{~nm}$, as shown in Fig. 1a. After high-pass filtering, the differential absorption spectrum (1 ppb km) of isoprene is shown in Fig. $1 \mathrm{~b}$. According to its differential absorption characteristics, the fitting band of isoprene is $202.71-227.72 \mathrm{~nm}$. Within this band, there are also absorptions of $\mathrm{NH}_{3}$ (Chen et al., 1999), $\mathrm{SO}_{2}$ (Wu et al., 2000), $\mathrm{NO}, \mathrm{NO}_{2}$ (Mérienne et al., 1995), $\mathrm{C}_{6} \mathrm{H}_{6}$ (Dawes et al., 2017), $\mathrm{C}_{7} \mathrm{H}_{8}$ (Serralheiro et al., 2015), etc. These high-resolution absorption cross sections are convoluted with the instrumental wavelength before being introduced into the spectral fitting. The absorption of NO used here was measured in the laboratory with known concentrations of gas by using the same instrument. Therefore, the absorption of these components is also considered in the process of spectral retrieval. Figure 2 displays an example of the spectral fitting of an actual atmospheric spectrum (measured on 8 July 2018 at 12:47 LT). In Fig. 2a, the black line is the measured spectrum, and the red line is the fitting spectrum (0.79 ppb isoprene, $2.83 \mathrm{ppb} \mathrm{NH}_{3}, 1.85 \mathrm{ppb} \mathrm{SO}_{2}, 1.42 \mathrm{ppb}$ $\mathrm{NO}, 4.94 \mathrm{ppb} \mathrm{NO}_{2}, 0.01 \mathrm{ppb}_{6} \mathrm{H}_{6}, 2.20 \mathrm{ppb} \mathrm{C}_{7} \mathrm{H}_{8}$ ), while the fitting residual (standard deviation is $4.76 \times 10^{-4}$ ) is shown in Fig. 2i. The differential optical densities of isoprene and other interference trace gases are displayed in Fig. $2 b$ to $h$, respectively, of which the measurement error of isoprene

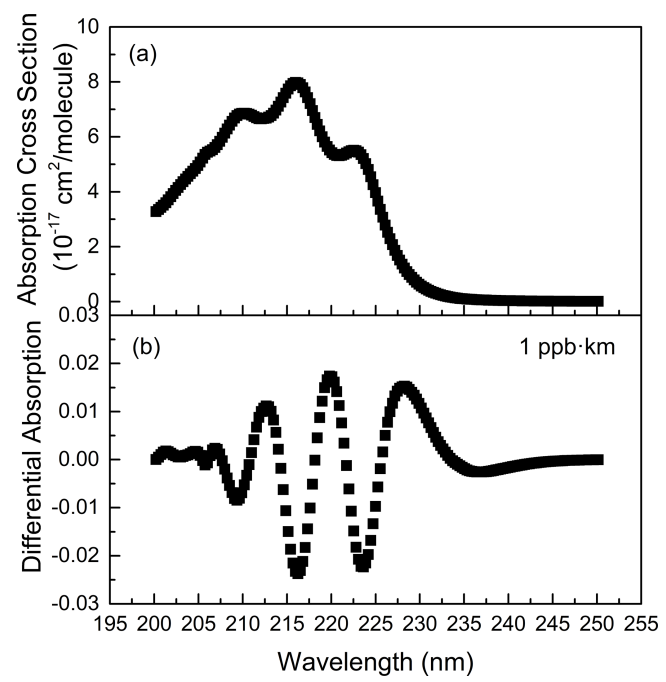

Figure 1. The absorption cross section and differential absorption spectrum of isoprene in $1 \mathrm{ppb} \mathrm{km}$.

is about $10.6 \%$ according to the method proposed by Stutz and Platt (1996).

\subsection{Calibration experiment}

To verify the accuracy of the measurement results, isoprene gas with a known concentration was used to calibrate the instrument in the laboratory. The method is to close the emitting telescope and receiving telescope (close to zero optical path) in the laboratory, and then a series absorption cell is placed between the telescopes. Isoprene gas (10 ppm) was injected into the cells at a constant flow rate of $100 \mathrm{~mL} \mathrm{~min}^{-1}$, 


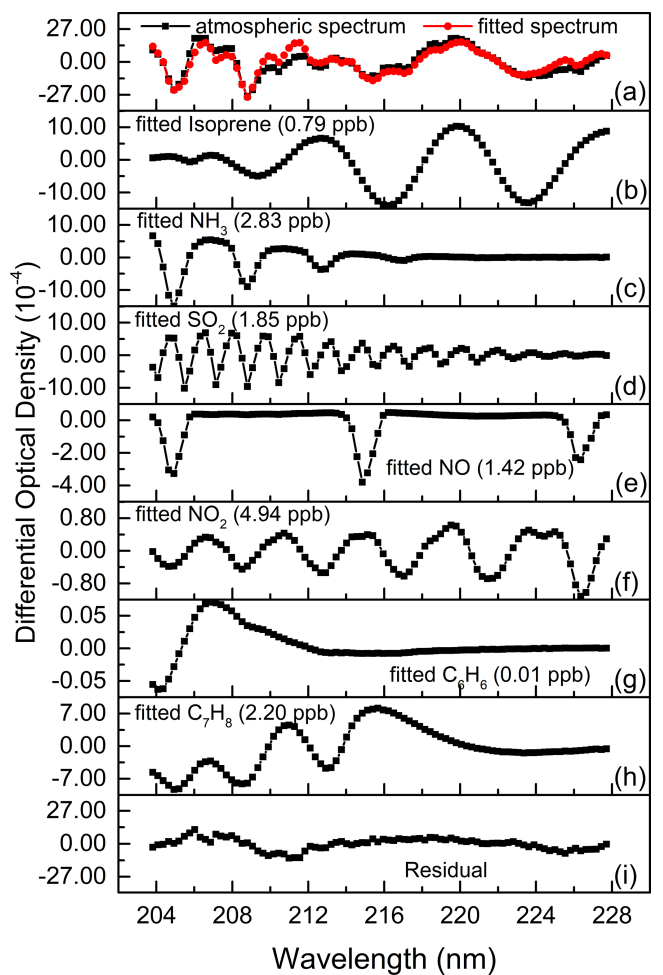

Figure 2. Example of the spectral fitting of an actual atmospheric spectrum (measured on 8 July 2018 at 12:47 LT).

Table 2. The calibration results in different gas cell combinations.

\begin{tabular}{lrr}
\hline Length of cells & $C_{\mathrm{E}}(\mathrm{ppb})$ & $C_{\mathrm{M}}(\mathrm{ppb})$ \\
\hline empty & 0 & $0.01 \pm 0.005$ \\
$2 \mathrm{~cm}$ & 2.00 & $1.88 \pm 0.004$ \\
$4 \mathrm{~cm}$ & 4.00 & $3.61 \pm 0.019$ \\
$2 \mathrm{~cm}+4 \mathrm{~cm}$ & 6.00 & $5.40 \pm 0.009$ \\
$4 \mathrm{~cm}+4 \mathrm{~cm}$ & 8.00 & $7.44 \pm 0.030$ \\
$2 \mathrm{~cm}+4 \mathrm{~cm}+4 \mathrm{~cm}$ & 10.00 & $9.42 \pm 0.010$ \\
\hline
\end{tabular}

and then the corresponding concentration under different cell combinations was measured, as shown in Fig. 3.

The absorption cell group is composed of one $2 \mathrm{~cm}$ and two $4 \mathrm{~cm}$ long cells in series. When using different combinations of cells, different equivalent concentrations $\left(C_{\mathrm{E}}\right)$ (equivalent to the average concentration in the $100 \mathrm{~m}$ optical path) can be obtained. The specific combination and corresponding equivalent concentrations, as well as the actual measurement concentrations $\left(C_{\mathrm{M}}\right)$, are shown in Table 2.

Figure 4 shows the linear fit of the calibration results. The ordinate in the figure is the equivalent concentration, and the abscissa is the measured concentration. For six measuring points, including the zero point, the linear fitting correlation coefficient $R$ is 0.9995 . The relationship between the equivalent concentration and the measured concentration is shown in Eq. (1). For future measurement results of the actual atmo- sphere, Eq. (1) will be used to calibrate the measured data.

$C_{\mathrm{E}}=(0.061 \pm 0.024)+(1.067 \pm 0.004) \times C_{\mathrm{M}}$

\section{Field comparison experiment and discussion}

\subsection{Comparison with online VOC results}

To further verify the reliability of the DOAS method in actual atmospheric measurements, in July 2018, the field measurement results of the DOAS were compared with the online VOC (TH-300B online VOC monitoring system) analyzer (Zhu et al., 2020), which is based on the GC-MS technology. The DOAS instrument is installed on the seventh floor of the Environmental Science Building $\left(31.344^{\circ} \mathrm{N}, 121.518^{\circ} \mathrm{E}\right)$ on Jiangwan Campus of Fudan University, as shown in Fig. 5. The optical path is about $25 \mathrm{~m}$ above the ground. The transmitting telescope is in the western part of the building (A in Fig. 5), while the receiving telescope is in the eastern part (B in Fig. 5). The distance between the telescopes is $75 \mathrm{~m}$. The online VOC instrument is located at Xinjiangwan City monitoring station of the Shanghai Environmental Monitoring Center (C in Fig. 5). The straight-line distance is about $0.5 \mathrm{~km}$ to the south of the DOAS instrument. The coverage rate of plants around the observation sites was high, mainly including pine, camphor, etc., and a large number of lawns were also distributed. Meteorological parameters were recorded by an automatic weather station (CAMS620-HM, Huatron Technology Co. Ltd) co-located with the DOAS instrument.

The comparison experiment was carried out from 1 to 23 July 2018. The temporal resolution of the DOAS was $1 \mathrm{~min}$, while that of the online VOCs was $1 \mathrm{~h}$. To match the temporal resolution, the DOAS data were averaged hourly. Moreover, the measured spectra with low light intensity and high integration time were excluded from the spectral fitting and data processing, which were mainly due to the unfavorable weather conditions influencing the measurements. The spectra were also corrected for offset before introducing fitting. Figure 6a shows the time series of the isoprene data measured by these two instruments, which are in good agreement. The average values of DOAS and online VOCs were 0.325 and $0.217 \mathrm{ppb}$, respectively, and the standard deviations (SDs) were $0.254 \mathrm{ppb}(N=551)$ and $0.257 \mathrm{ppb}(N=$ $466)$, respectively. The average value of the DOAS results is higher than that of the online VOCs mainly because, at night, DOAS can still detect a certain concentration in most cases, most of which range between $0.02-0.10 \mathrm{ppb}$, while most of the online VOC data range between $0-0.05 \mathrm{ppb}$. Due to the missing online VOC data during the comparison period, in total 466 sets of hourly data were used to analyze the correlation between these two instruments. As shown in Fig. 6b, the correlation coefficient is 0.85 , and the slope is 0.86 . 


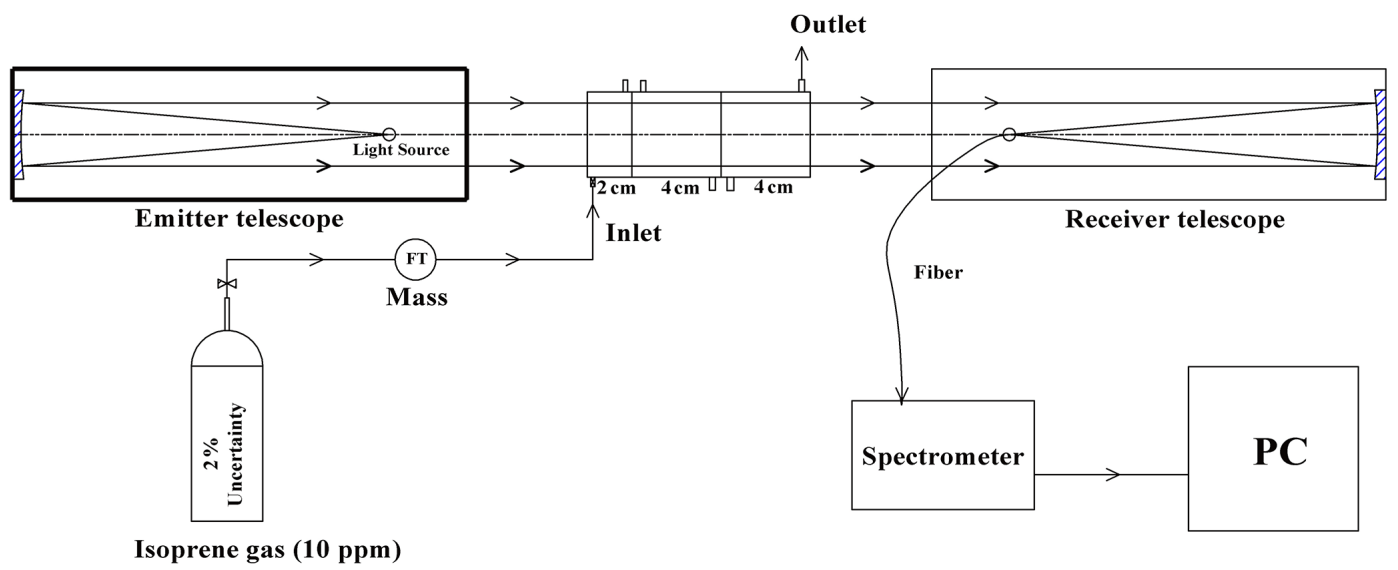

Figure 3. The scheme of the calibration system.

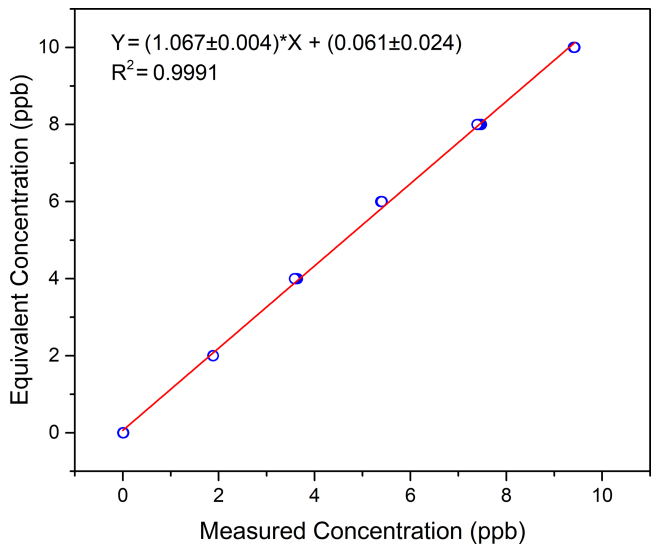

Figure 4. The linear fitting of calibration results for isoprene measurement.

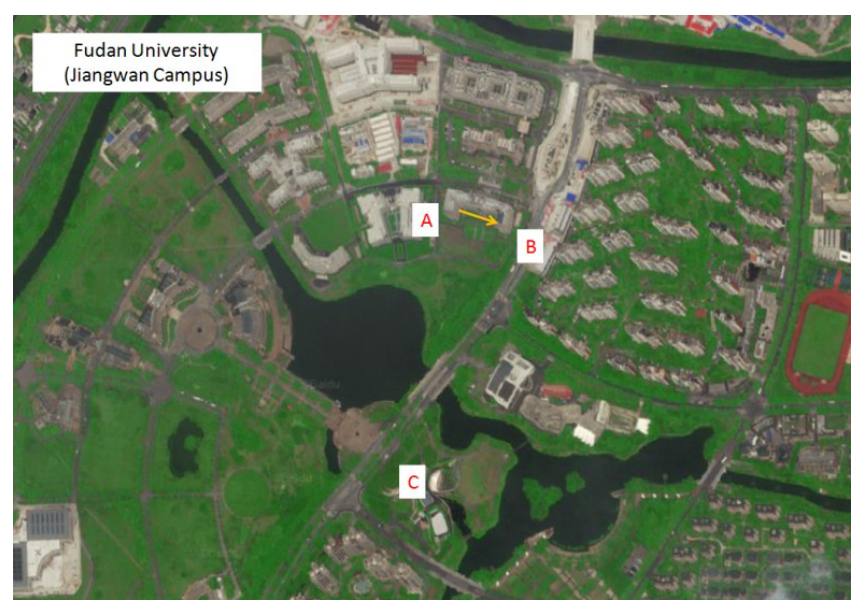

Figure 5. Field measurement sites of DOAS and online VOCs, A is the transmitting telescope, $\mathrm{B}$ is the receiving telescope, and $\mathrm{C}$ is the online VOCs, and the yellow arrow is the light path of the DOAS. This map is sourced from (C) Baidu.
The main reason for the difference in DOAS and online VOC results is that the sampling and measurement heights of the two instruments are different. The light path of the DOAS is about $25 \mathrm{~m}$ above the ground, while the sampling height of online VOC instrument is about $10 \mathrm{~m}$. In addition to the $500 \mathrm{~m}$ distance between these two sites, the air sampled by the VOC analyzer or penetrated by the DOAS light beam is completely different. The inhomogeneous spatial distribution of isoprene will lead to different data results between the two instruments. Considering that the sampling of online VOCs occurs through the sampling tube, isoprene will be more or less lost during the sampling process, which could account for up to $10 \%$ in some high-carbon VOCs (EPA, 2019). To ensure the authenticity and accuracy of the observed data, the working status and response of the TH-300B monitoring system were inspected every day. Daily calibrations were performed automatically at 00:00 to 01:00 LT. In addition, the external standard method for the FID (flame ionization detector) and the internal standard method for the MS were adopted. Implementing the daily calibration at midnight could move the online VOC-observed value close to the zero point, which may deviate from the actual abundance. Since the observation is in summer, there is also a very high temperature at night during the observation period, i.e., $27.1^{\circ} \mathrm{C}$ (19:00-06:00 LT next morning). In addition, the release of isoprene produced by the leaves of plants in the daytime is delayed to some extent, resulting in a certain concentration of isoprene remaining at night, so we think the DOAS data are more reasonable. These two reasons will eventually lead to DOAS measurement results higher than online VOC instruments, especially when the isoprene concentration is very low at night, and the difference is more obvious. On the other hand, the error of the DOAS method could also be a possible reason for the difference with the VOC analyzer.

It can also be seen in Fig. $6 \mathrm{~b}$ that when the isoprene concentration is higher than $0.5 \mathrm{ppb}$, the measurement results of the two instruments show large scattering. The different mea- 

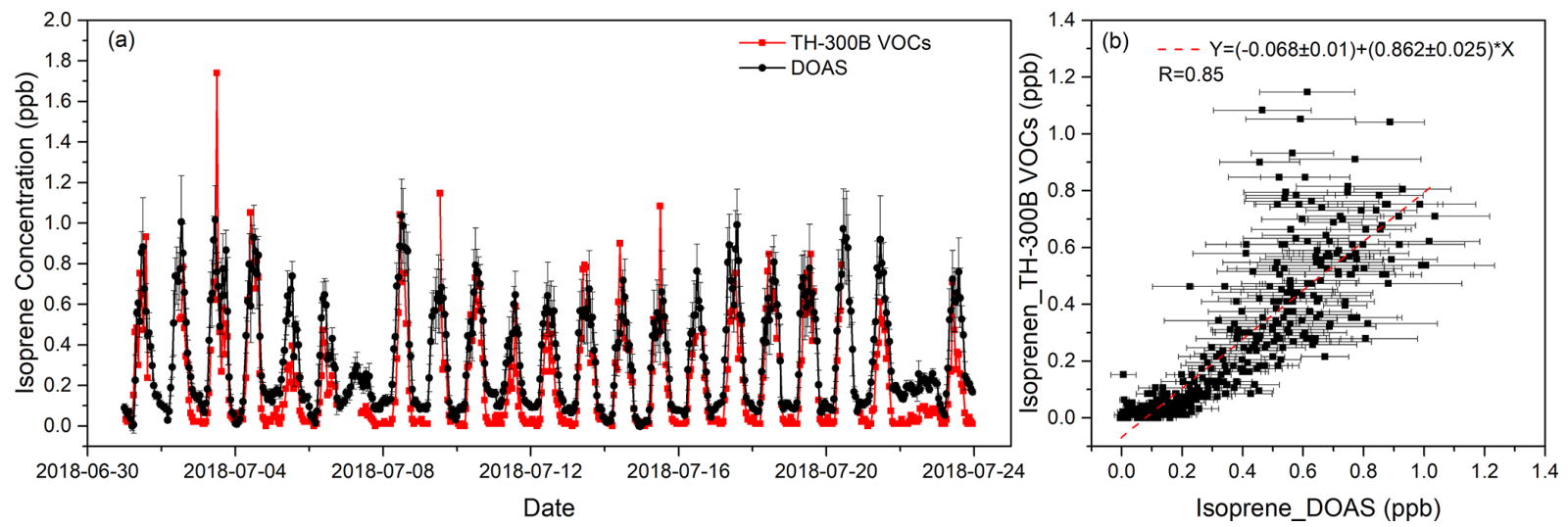

Figure 6. The comparison of hourly isoprene measured by DOAS and online VOCs during the field measurement.

surement principles, especially the difference in sampling time, can also cause scattering of the results of the two instruments. Online VOCs only have about $50 \%$ of the time $(1 \mathrm{~h})$ to be used for sampling, while the rest of the time is used for analysis. However, DOAS is an almost continuous measurement with just a small part of the time to be used for analysis (about $1 \mathrm{~s} \mathrm{~min}^{-1}$ ); this difference will affect the consistency of the results. Meanwhile, there are various vegetation types between the instruments. When the wind direction changes, the emission of this part of vegetation will also cause a difference between the results of the instruments. However, in general, DOAS and online VOC analyzers show a good agreement in the comparison of the mean and correlation of measured data.

\subsection{Detection limit evaluation}

The detection limit of DOAS mainly depends on the signalto-noise ratio of the spectrum. Under the condition of a zero light path in the laboratory, the zero noise (standard deviation of the results) of isoprene is $0.005 \mathrm{ppb}$, and the detection limit can be defined as 2 times the zero noise so that the detection limit of the system is $0.010 \mathrm{ppb}$ (HJ 654-2013, 2013). However, in real atmospheric measurements, it is difficult to determine the actual detection limit due to the varied environment and the interference of other gases. The detection limit of DOAS in a real atmosphere is mainly determined by the residual of spectral fitting. This residual mainly comes from the absorption of interfering substances, the change in lamp spectral intensity and structure, the spectral shift caused by the change of ambient temperature of the spectrometer, and the noise of the detector. Since the stability of the light source and spectrometer will influence the fitting residual and instrumental performance, temperature control was adopted for the spectrometer and operating ambient environment. To reduce the influence of these factors on the measurement, during the spectral fitting process, the absorption of interfering substances and the spectral structure of the lamp must be considered together with the isoprene absorption spectrum.
The lamp spectrum will also be introduced into the fitting process if an obvious lamp spectral structure was observed in the residual. At the same time, it is also necessary to calibrate the spectral drift. However, some residuals remain after spectral fitting due to possible imperfect reference spectra. Overall, the averaged measurement errors of isoprene were estimated to be lower than $20 \%$.

In the fitting band of isoprene, the absorption of NO, benzene and toluene are the main interference factors. The reason for the influence of NO is that there are three obvious absorption peaks of NO in the fitting band. After high-pass filtering, there is a component in the differential absorption cross section of NO similar to the variation frequency of isoprene's differential absorption spectrum. After an analysis of the measurement results, the impact of NO on isoprene is about $0.3 \%$ of its concentration. However, the effect of NO mainly occurs in the morning and evening rush hours. The influence of benzene and toluene is mainly due to their strong absorptions in the fitting band of the spectrum. Their presence will lead to a significant reduction in the spectral intensity in this band, resulting in a reduction in the signalto-noise ratio of the spectrum. During the comparison experiment, a high concentration of benzene or toluene occasionally occurs, resulting in a large fitting residual. Other aromatics, such as xylene and styrene, also absorb strongly in the fitting band, but because of their lower concentration in the natural atmosphere, their impacts on isoprene are significantly smaller than that of benzene and toluene. Although $\mathrm{NH}_{3}, \mathrm{SO}_{2}$ and $\mathrm{NO}_{2}$ have absorption in the fitting band, their differential absorption variation frequency is significantly higher than that of isoprene and only overlaps in parts of fitting band so that they have little influence on the isoprene measurement. Figure 7a shows the absorption cross sections of benzene, toluene and isoprene, while Fig. 7b illustrates the differential absorption spectra (1 ppb km) of NO, $\mathrm{SO}_{2}, \mathrm{NO}_{2}, \mathrm{NH}_{3}$ and isoprene obtained by applying high-pass filter, which is the same as the spectral fitting process. Moreover, the employment of the "clean" atmospheric spectrum, 


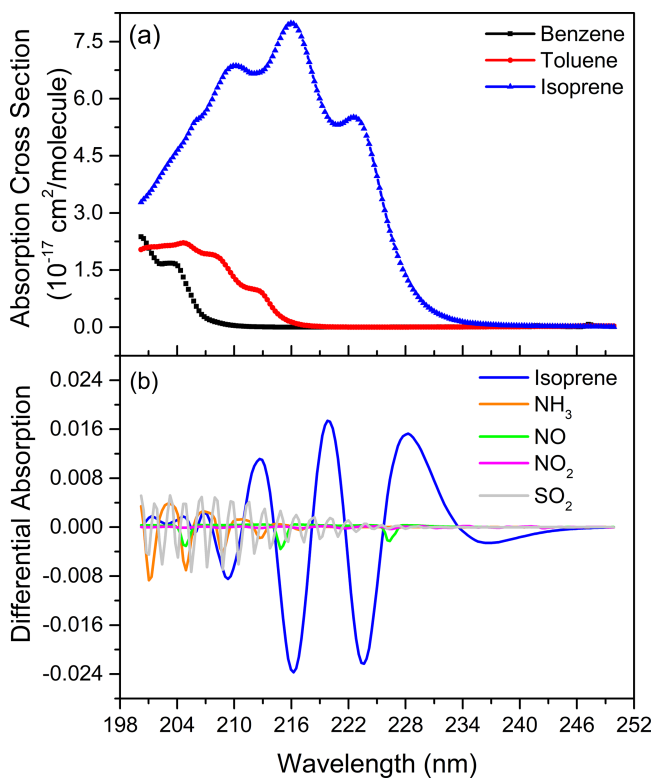

Figure 7. The absorption cross sections of benzene, toluene and isoprene (a), the differential absorption spectra ( $1 \mathrm{ppb} \mathrm{km})$ of NO, $\mathrm{SO}_{2}, \mathrm{NO}_{2}, \mathrm{NH}_{3}$ and isoprene (b).

instead of the reference spectrum without any absorption under a zero optical path, also introduces the uncertainty into the spectral fitting because it may contain little isoprene absorption.

Benzene, toluene, or $\mathrm{NO}, \mathrm{SO}_{2}, \mathrm{NO}_{2}$ and $\mathrm{NH}_{3}$ are present together with isoprene in the atmosphere. Therefore, their influences on isoprene measurement are common. To ensure the quality of the results, the data with a residual of more than 0.0005 are filtered out. In a total of 33120 sets of data during $23 \mathrm{~d}$ of observation, 1137 sets were filtered out, and the valid rate of data was $96.6 \%$. The average residual of all valid data is 0.000234 . To evaluate the detection limit of DOAS in a real atmospheric measurement, we calculated a statistic on 16387 sets of data with the concentration of isoprene lower than $0.1 \mathrm{ppb}$ (assuming that the isoprene in the atmosphere is close to zero at this time), and the standard deviation is $0.0499 \mathrm{ppb}$, so the detection limit of the DOAS instrument in the field measurement is no more than $0.1 \mathrm{ppb}$ (twice the standard deviation).

\section{Conclusion}

This paper introduces, for the first time, the continuous online measurement of isoprene in the atmosphere by means of DOAS in the band of 202.71-227.72 nm. Although the current measurements of isoprene mainly consist of GCMS, PTR-MS and CIMS methods, the DOAS method has the characteristics of high time resolution, rapid temporal response and simple operation. It is especially suitable for long-term online measurement in fields or forests where the travel is inconvenient, and the low cost of instrument is also conducive to building monitoring networks.

Under the condition of zero optical path in the laboratory, several equivalent concentrations were measured by using series absorption cells and known concentrations of isoprene gas. The correlation coefficient between the measured concentrations and the equivalent concentrations was 0.9996, and the slope was 1.065 , indicating that the instrument has good linearity and accuracy. After $23 \mathrm{~d}$ of field comparisons, there was a good correlation between the results of the DOAS and online VOC instrument, with a correlation coefficient of 0.85 and a slope of 0.86 . Considering the differences in measurement principles and the sampled air, the comparison results show good agreement between these two instruments.

To evaluate the detection limit of the DOAS instrument under actual atmospheric measurements, this study proposes to calculate the standard deviation of all the data when the measured concentration of isoprene in the ambient air is close to zero ( $<0.1 \mathrm{ppb}, n=16387)$. It is estimated that the detection limit of DOAS is no more than $0.1 \mathrm{ppb}$ under a measurement light path of $75 \mathrm{~m}$. Therefore, DOAS is suitable for long-term monitoring in cities or areas with large vegetation coverage.

Data availability. Data are available at https://doi.org/10.17632/ 489mvgbsxg.4 (Zhou, 2020).

Author contributions. The study was designed by SG and BZ. Laboratory and field experiments were performed by YG, RZ and YY. Spectral analysis and data processing were done by BZ, JZ and CG. The paper was written by BZ, SW and SG, with contributions from all authors.

Competing interests. The authors declare that they have no conflict of interest.

Acknowledgements. We would like to thank the Shanghai Environmental Monitoring Center for supporting the online VOC analyzer measurement. We thank the National Key Research and Development Program of China and the National Natural Science Foundation of China for their financial support.

Financial support. This research has been supported by the National Key Research and Development Program of China (grant nos. 2017YFC0210002, 2016YFC0200401) and the National Natural Science Foundation of China (grant nos. 21777026, 41775113, 21976031, 42075097).

Review statement. This paper was edited by Jochen Stutz and reviewed by two anonymous referees. 


\section{References}

Aydin, Y. M., Yaman, B., Koca, H., Dasdemir, O., Kara, M., Altiok, H., Dumanoglu, Y., Bayram A., Tolunay, D., Odabasi, M., and Elbir, T.: Biogenic volatile organic compound (BVOC) emissions from forested areas in Turkey: determination of specific emission rates for thirty-one tree species, Sci. Total Environ., 490, 239253, https://doi.org/10.1016/j.scitotenv.2014.04.132, 2014.

Bai, J.: Estimation of the isoprene emission from the Inner Mongolia grassland, Atmos. Pollut. Res., 6, 406-414, https://doi.org/10.5094/APR.2015.045, 2015.

Blake, R. S., Monks, P. S., and Ellis, A. M.: Proton-Transfer Reaction Mass Spectrometry, Chem. Rev., 109, 861-896, https://doi.org/10.1021/cr800364q, 2009.

Bolas, C. G., Ferracci, V., Robinson, A. D., Mead, M. I., Nadzir, M. S. M., Pyle, J. A., Jones, R. L., and Harris, N. R. P.: iDirac: a field-portable instrument for long-term autonomous measurements of isoprene and selected VOCs, Atmos. Meas. Tech., 13, 821-838, https://doi.org/10.5194/amt-13-821-2020, 2020.

Brauer, C. S., Blake, T. A., Guenther, A. B., Sharpe, S. W., Sams, R. L., and Johnson, T. J.: Quantitative infrared absorption cross sections of isoprene for atmospheric measurements, Atmos. Meas. Tech., 7, 3839-3847, https://doi.org/10.5194/amt-7-3839-2014, 2014.

Chen, F. Z., Judge, D. L., Wu, C. Y. R., and Caldwell, J.: Low and room temperature photoabsorption cross sections of $\mathrm{NH}_{3}$ in the UV region, Planet. Space Sci., 47, 261-266, https://doi.org/10.1016/S0032-0633(98)00074-9, 1999.

Chen, T., Xue, L., Zheng, P., Zhang, Y., Liu, Y., Sun, J., Han, G., Li, H., Zhang, X., Li, Y., Li, H., Dong, C., Xu, F., Zhang, Q., and Wang, W.: Volatile organic compounds and ozone air pollution in an oil production region in northern China, Atmos. Chem. Phys., 20, 7069-7086, https://doi.org/10.5194/acp20-7069-2020, 2020.

Dawes, A., Pascual, N., Hoffmann, S. V., Jones, N. C., and Mason, N. J.: Vacuum ultraviolet photoabsorption spectroscopy of crystalline and amorphous benzene, Phys. Chem. Chem. Phys., 19, 27544-27555, https://doi.org/10.1039/c7cp05319c, 2017.

Eerdekens, G., Ganzeveld, L., Vilà-Guerau de Arellano, J., Klüpfel, T., Sinha, V., Yassaa, N., Williams, J., Harder, H., Kubistin, D., Martinez, M., and Lelieveld, J.: Flux estimates of isoprene, methanol and acetone from airborne PTR-MS measurements over the tropical rainforest during the GABRIEL 2005 campaign, Atmos. Chem. Phys., 9, 4207-4227, https://doi.org/10.5194/acp9-4207-2009, 2009.

EPA: Technical Assistance Document for Sampling and Analysis of Ozone Precursors for the Photochemical Assessment Monitoring Stations Program, U.S. Environmental Protection Agency, EPA-454/B-19-004, available at: https://www.epa.gov/amtic/ pams-technical-assistance-document-tad (last access: 2 April 2021), 2019.

Gong, D., Wang, H., Zhang, S., Wang, Y., Liu, S. C., Guo, H., Shao, M., He, C., Chen, D., He, L., Zhou, L., Morawska, L., Zhang, Y., and Wang, B.: Low-level summertime isoprene observed at a forested mountaintop site in southern China: implications for strong regional atmospheric oxidative capacity, Atmos. Chem. Phys., 18, 14417-14432, https://doi.org/10.5194/acp-18-144172018, 2018.

HJ 654-2013: Specifications and Test Procedures for Ambient Air Quality Continuous Automated Monitoring System for $\mathrm{SO}_{2}, \mathrm{NO}_{2}, \mathrm{O}_{3}$ and $\mathrm{CO}$, national standard of China, available at: http://www.cnemc.cn/jcgf/dqhj/201711/t20171108_ 647283.shtml (last access: 2 April 2021), 2013 (in Chinese).

Leibrock, E. and Huey, L. G.: Ion chemistry for the detection of isoprene and other volatile organic compounds in ambient air, Geophys. Res. Lett., 27, 1719-1722, https://doi.org/10.1029/1999GL010804, 2000.

Leibrock, E., Huey, L. G., Goldan, P. D., Kuster, W. C., Williams, E., and Fehsenfeld, F. C.: Ground-based intercomparison of two isoprene measurement techniques, Atmos. Chem. Phys., 3, 6772, https://doi.org/10.5194/acp-3-67-2003, 2003.

Lian, H. Y., Pang, S. F., He, X., Yang, M., Ma, J. B., and Zhang, Y. H.: Heterogeneous reactions of isoprene and ozone on alpha- $\mathrm{Al}_{2} \mathrm{O}_{3}$ : The suppression effect of relative humidity, Chemosphere, 240, 124744, https://doi.org/10.1016/j.chemosphere.2019.124744, 2020.

Lu, K., Guo, S., Tan, Z., Wang, H., Shang, D., Liu, Y., Li, X., $\mathrm{Wu}, \mathrm{Z} ., \mathrm{Hu}, \mathrm{M}$. , and Zhang, Y.: Exploring atmospheric freeradical chemistry in China: the self-cleansing capacity and the formation of secondary air pollution, Natl. Sci. Rev., 6, 579-594, https://doi.org/10.1093/nsr/nwy073, 2018.

Martins, G., Ferreira-Rodrigues, A. M., Rodrigues, F. N., de Souza, G. G. B., Mason, N. J., Eden, S., Duflot, D., Flament, J.-P., Hoffmann, S. V., Delwiche, J., Hubin-Franskin, M.J., and Limão-Vieira, P.: Valence shell electronic spectroscopy of isoprene studied by theoretical calculations and by electron scattering, photoelectron, and absolute photoabsorption measurements, Phys. Chem. Chem. Phys., 11, 11219-11231, https://doi.org/10.1039/B916620C, 2009.

Mérienne, M. F., Jenouvrier, A., and Coquart, B.: The $\mathrm{NO}_{2}$ absorption spectrum. I: Absorption cross-sections at ambient temperature in the 300-500 nm region, J. Atmos. Chem., 20, 281-297, https://doi.org/10.1007/BF00694498, 1995.

Platt, U. and Stutz, J.: Differential Optical Absorption Spectroscopy, Principles and Applications, Springer, 138-141, https://doi.org/10.1007/978-3-540-75776-4, 2008.

Platt, U., Perner, D., and Pätz, H.: Simultaneous measurement of atmospheric $\mathrm{CH}_{2} \mathrm{O}, \mathrm{O}_{3}$, and $\mathrm{NO}_{2}$ by differential optical absorption, J. Geophys. Res., 84, 6329-6335, 1979.

Platt, U., Perner, D., Harris, G. W., Winer, A. M., and Pitts, J. N.: Detection of $\mathrm{NO}_{3}$ inthe polluted troposphere by differential optical absorption, Geophys. Res. Lett., 7, 89-92, https://doi.org/10.1029/GL007i001p00089, 1980.

Serralheiro, C., Duflot, D., Ferreira, F. da Silva, Hoffmann, S. V., Jones, N. C., Mason, N. J., Mendes, B., and LimãoVieira, P.: Toluene valence and Rydberg excitations as studied by ab initio calculations and vacuum ultraviolet (VUV) synchrotron radiation, J. Phys. Chem. A, 119, 9059-9069, https://doi.org/10.1021/acs.jpca.5b05080, 2015.

Sindelarova, K., Granier, C., Bouarar, I., Guenther, A., Tilmes, S., Stavrakou, T., Müller, J.-F., Kuhn, U., Stefani, P., and Knorr, W.: Global data set of biogenic VOC emissions calculated by the MEGAN model over the last 30 years, Atmos. Chem. Phys., 14, 9317-9341, https://doi.org/10.5194/acp-14-9317-2014, 2014.

Stutz, J. and Platt, U.: Numerical analysis and estimation of the statistical error of differential optical absorption spectroscopy measurements with least-squares methods, Appl. Opt., 35, 60416053, https://doi.org/10.1364/AO.35.006041, 1996. 
Wu, C. Y. R.,Yang, B. W., Chen, F. Z., Judge, D. L., Caldwell, J., and Trafton, L. M.: Measurements of high-, room-, and lowtemperature photoabsorption cross sections of $\mathrm{SO}_{2}$ in the 2080to 2950-A region,with application to Io, Icarus, 145, 289-296, https://doi.org/10.1006/icar.1999.6322, 2000.

Xie, Y., Paulot, F., Carter, W. P. L., Nolte, C. G., Luecken, D. J., Hutzell, W. T., Wennberg, P. O., Cohen, R. C., and Pinder, R. W.: Understanding the impact of recent advances in isoprene photooxidation on simulations of regional air quality, Atmos. Chem. Phys., 13, 8439-8455, https://doi.org/10.5194/acp13-8439-2013, 2013.

Zeng, Y., Shen, Z., Zhang, T., Lu, D., Li, G., Lei, Y., Feng, T., Wang, X., Huang, Y., Zhang, Q., Xu, H., Wang, Q., and Cao, J.: Optical property variations from a precursor (isoprene) to its atmospheric oxidation products, Atmos. Environ., 193, 198-204, https://doi.org/10.1016/j.atmosenv.2018.09.017, 2018.

Zhang, X., Huang, T., Zhang, L., Shen, Y., Zhao, Y., Gao, H., Mao, X., Jia, C., and Ma, J.: Three-North Shelter Forest Program contribution to long-term increasing trends of biogenic isoprene emissions in northern China, Atmos. Chem. Phys., 16, 69496960, https://doi.org/10.5194/acp-16-6949-2016, 2016.
Zheng, Y., Unger, N., Barkley, M. P., and Yue, X.: Relationships between photosynthesis and formaldehyde as a probe of isoprene emission, Atmos. Chem. Phys., 15, 8559-8576, https://doi.org/10.5194/acp-15-8559-2015, 2015.

Zhou, B.: Data for "Study on the measurement of isoprene by Differential Optical Absorption Spectroscopy”, Mendeley Data, V3, https://doi.org/10.17632/489mvgbsxg.4, 2020.

Zhu, J., Wang, S., Wang, H., Jing, S., Lou, S., Saiz-Lopez, A., and Zhou, B.: Observationally constrained modeling of atmospheric oxidation capacity and photochemical reactivity in Shanghai, China, Atmos. Chem. Phys., 20, 1217-1232, https://doi.org/10.5194/acp-20-1217-2020, 2020. 